\title{
The Role of the Reverse Fault on the Permeability Evolution in Mining Coal
}

\author{
Rui Zhou $\mathbb{D}^{1},{ }^{1}$ Yujin Qin $\mathbb{D}^{1},{ }^{1}$ and Yang $\mathrm{Hu} \mathbb{D}^{1,2}$ \\ ${ }^{1}$ State Key Laboratory of Coal Mine Safety Technology, China Coal Technology \& Engineering Group Shenyang Research Institute, \\ Shenfu Demonstration Zone 113122, China \\ ${ }^{2}$ School of Mechanics and Civil Engineering, China University of Mining and Technology, Xuzhou, Jiangsu 221116, China
}

Correspondence should be addressed to Rui Zhou; zhouruicumt@126.com

Received 6 June 2021; Accepted 22 July 2021; Published 11 August 2021

Academic Editor: Yang Wang

Copyright (C) 2021 Rui Zhou et al. This is an open access article distributed under the Creative Commons Attribution License, which permits unrestricted use, distribution, and reproduction in any medium, provided the original work is properly cited.

To prevent and control the coal seam gas disaster affected by the reverse fault, we performed gas seepage tests, which consider stress-loading and unloading schemes, to investigate the stress change and coal permeability of the mining coal with reverse fault. The experimental results show that the mechanical behavior and permeability change of the mining coal are related to the distance between the coal and the reverse fault. The stress concentration coefficient of the coal body gradually increases. The closer is the distance between the coal and the reverse fault, the larger are the deviatoric stress peak and strain. In comparison with the coal sample M1 that is $5 \mathrm{~m}$ away from the reverse fault, the deviatoric stress peak and axial strain of the coal sample M3, $35 \mathrm{~m}$ away from the reverse fault, increase by $40.74 \%$ and $26.73 \%$, respectively. In this stage, the permeability of M1, M2, and M3 coal samples increases by $22.1 \%, 28.0 \%$, and $36.7 \%$, respectively. In another stage, the stress concentration coefficient of coal increases to the peak and then decreases, causing the deviatoric stress peak and strain of coal to rise first and then fall. In comparison with the coal sample M4 that is $65 \mathrm{~m}$ away from the reverse fault, the deviatoric stress peak and axial strain of coal sample M6, $5 \mathrm{~m}$ away from the reverse fault, decrease by $29.48 \%$ and $5.55 \%$, respectively. The permeability of coal samples M4, M5, and M6 increases by 23.6\%, 37.2\%, and 20.8\%, respectively. Based on the gas seepage test results, we established the permeability model of mining-induced coal under the influence of a reverse fault, with consideration of the volume changes of coal fractures induced by adsorption and desorption. In the model, the variations of permeability in both stages of the prepeak and postpeak were deduced, which was verified with the experimental data. The verification results demonstrate that the proposed model has the capacity to predict the permeability evolution of mining coal under the influence of a reverse fault.

\section{Introduction}

The geological fault structures are recognized as the reason of earthquakes, seism, gas leakage, and outburst [1-5]. The gas burst accidents in the Beipiao mining area, Jiaozuo mining area, Yangquan mining area, and Huainan mining area, etc. have been identified to be related to the structure dominated by faults $[6,7]$. The aperture of normal fault trends to widening with tensile stress, which provides a conductive path for gas flow, while the reverse fault contributes to the seal fault with compressive stress. Additionally, the stress concentration caused by horizontal compression leads to narrowing the gas flow channels and reducing coal permeability. The resulted accumulation of high-energy gas improves the possi- bility of coal and gas outburst accidents in the mining coal. Therefore, the reverse fault structure plays a predominate role in the gas accidents. The gas accumulates in the area near the reverse fault stably.

Because of mining, the stress changes in the area near the fault result in the variation of coal permeability that causes the gushing of accumulated gas and gas outburst accidents. To prevent and control the coal-gas disaster in areas affected by the reverse fault, it is necessary to study the roles of the reverse fault on the stress evolution and permeability change in the mining coal.

The permeability of coal is one of the key parameters that controls the gas migration and predicts the gas gushing amount. Moreover, it is also a key factor to explore the 


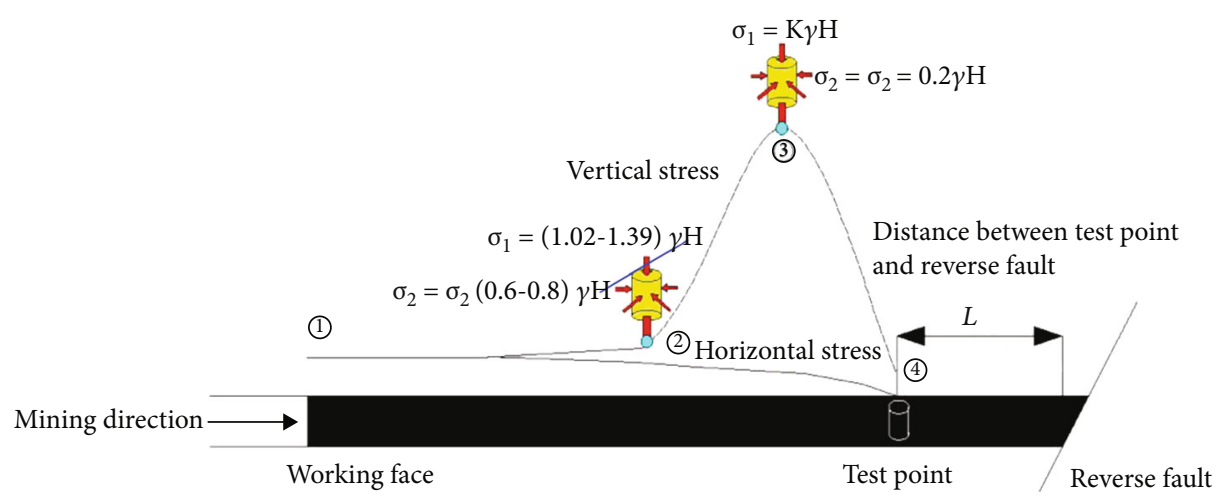

FIgURE 1: Stress variation of coal with a reverse fault.

mechanism of coal and gas outburst. The permeability of mining-induced coal body as a dynamic characterization parameter of gas seepage during coal mining has been gaining attention in the field of gas burst. The influence of coal structure [8-10], surrounding rock stress $[11,12]$, pore pressure $[13,14]$, and other factors on coal permeability have been systematically studied. A series of coal permeability models have been proposed. The isotropy permeability models of coal refer to two types of models, called strain-dependent and stress-dependent permeability models [12, 15-18].

The permeability characteristics of the mining coal are related to the bearing stress. The gas pressure gradient of the driving face with faults was significantly higher than that without faults [19]. When the mining face passed through the fault, the mining disturbance would cause the activation of the fault that causes a change in the permeability of coal and rock mass on both sides of the fault. Meanwhile, due to the release of mining-induced concentrated stress and residual tectonic stress, coal and gas outburst occurs more easily [20]. According to the law of gas seepage in mining coal, many classic permeability models of mining coal body have been proposed, which establish the relationship between coal permeability and effective stress or effective horizontal stress. These permeability models could systematically characterize the behaviors of gas seepage in mining coal body. However, there are few studies on the evolution of coal permeability with consideration of the influence of a reverse fault.

In this paper, the gas seepage tests with loading and unloading conditions are carried out to investigate the permeability evolution of coal samples since the stress variation characteristics of the coal body in the reverse fault area. Then, we propose the permeability models for the prepeak and postpeak stages. Moreover, the accuracy of the models is verified with the tested results.

\section{Test Study on Stress and Permeability of Mining Coal with a Reverse Fault}

2.1. Test Plan. The stress change of mining coal in the area near the reverse fault is shown in Figure 1 [21].

With the decrease of the distance away from the reverse fault, the vertical stress of coal began to increase obviously.
The vertical stress value of the coal could be generalized as $(0.6-0.8) \mathrm{K} \cdot \gamma \cdot \mathrm{H}$. The test point was in the stress concentration area in front of the working face. The vertical stress value reached the maximum $K \cdot \gamma \cdot H$. The stress concentration coefficient $K$ was related to the distance $L$ from the reverse fault. Two kinds of stress changes would occur:

(a) First, the stress concentration coefficient of mining coal gradually increased. In this situation, the bearing capacity of the coal body was below its strength. The coal stress in front of the working face gradually increased

(b) Second, the stress concentration coefficient of mining coal increased first. Then, when the bearing capacity of the coal exceeded its strength, the coal body is destructed and could not be effectively carried, decreasing the stress concentration coefficient of the coal

To accurately acquire the characteristics of gas seepage in mining coal with reverse fault, the test is carried out under the similar condition of stress change in the field. The field stress undergoes a transition from initial stress state to mining-induced stress state, in which the vertical stress increases and the horizontal stress decreases. Therefore, the triaxial loading schemes are designed in the seepage test, in which the mining-induced stress is reproduced through the stress change of loading and unloading. The vertical stress is simulated by axial pressure. The horizontal stress was simulated by confining pressure to revert the stress change law under different distances between the mining-induced coal and reverse fault. This paper mainly analyzed the change of the stress concentration degree and permeability variation of mining coal at the different positions away from the reverse fault. Thus, the horizontal stress is assumed to equal the vertical stress in the initial state. Additionally, the influence of pore pressure is neglected. Two groups of gas seepage tests are designed according to the two change laws of stress concentration coefficient of mining-induced coal with a reverse fault. The first group of gas seepage tests simulated the case that the stress concentration coefficient of coal increases with an increment of the distance between mining coal and reverse fault; the second group simulated the case that the coal stress concentration coefficient increased first 
and then decreased. Three loading schemes were designed for each group of tests to study the coal stress and permeability at different locations of the reverse fault distance. The details are shown as follows:

(1) The first group of gas seepage tests: in the first group of seepage tests, three loading schemes were designed. Schemes 1, 2, and 3 simulated the stress change of mining-induced coal body at $65 \mathrm{~m}, 35 \mathrm{~m}$, and $5 \mathrm{~m}$ away from the reverse fault, respectively. The stress concentration coefficient was set as $1.5,2.0$, and 2.5, respectively. To facilitate the comparative analysis of the influence of coal stress change on gas seepage, the gas pressure was set as $1 \mathrm{MPa}$. Each coal sample is loaded in three stages: initial stage, first stage, and second stage. The details for the test are described as follows:

(a) In the initial stage, the coal stress without mining-induced influence was simulated. The initial stress of the three schemes was set as $15 \mathrm{MPa}$ and the loading rate as $0.0083 \mathrm{MPa} / \mathrm{s}$ [22]

(b) In the first stage, the simulated coal body was in the position where stress was significantly increased, and the vertical stress of the coal body increased significantly. According to the conclusion that the coal body stress was generalized into $(1.02-1.39) \gamma \cdot H$ and set at $1.3 \gamma \cdot H$, and the horizontal stress corresponded to the vertical stress, which was adjusted through the unloading rate

(c) In the second stage, the coal was simulated to be in the stress concentration area until the coal was destructed. In Scheme 1, the loading rate was set as $0.0083 \mathrm{MPa} / \mathrm{s}$. The loading rates of Scheme 2 and Scheme 3 are $0.0083 \mathrm{MPa} / \mathrm{s}$ and $0.0166 \mathrm{MPa} / \mathrm{s}$, respectively. To acquire the mechanical behavior and gas seepage characteristic parameters of coal samples after destruction, displacement control was adopted in the postpeak process

(2) The second group of seepage tests: the second group of seepage tests simulated the case that the coal stress concentration coefficient first increased and then decreased with the decrease of the distance between the mining-induced coal body and the reverse fault under the influence of reverse fault. Three loading schemes were designed as the loading rates of Schemes 4, 5 and 6, respectively. Other settings are the same as those in the first group of gas seepage tests.

2.2. Test Equipment and Preparation of Coal Samples. A multiphysics coupling test system, as shown in Figure 2, is used in the test with the maximum axial pressure of the system up to $380 \mathrm{MPa}$, the maximum confining pressure up to $100 \mathrm{MPa}$, and the maximum temperature of the system up to $150^{\circ} \mathrm{C}$.

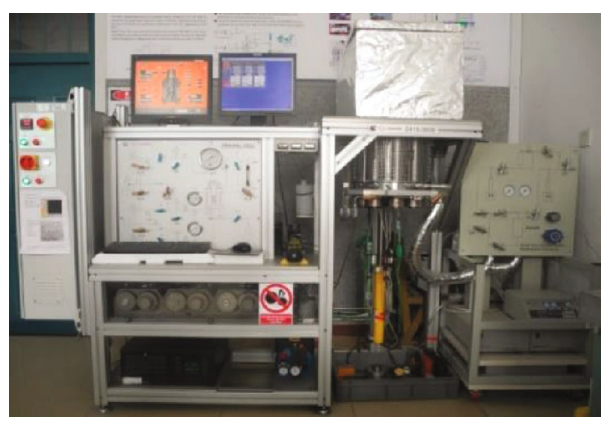

FIgUre 2: The multiphysics coupling test system.

The test pressure, gas pressure, gas volume, coal sample deformation, and other parameters that change with time are recorded by the acquisition system on time. The porosity, the amount of free gas, the swelling deformation caused by the amount of absorbed gas, and the permeability of gas are measured simultaneously under the combined action of the deviatoric stress, hydrostatic pressure, temperature, and other factors. The representative coal sample with good integrity is selected. A drilling sample machine is used to drill a cylinder core with a diameter of $50 \mathrm{~mm}$ from the complete coal block. A coal and rock cutting machine was used to cut the coal core into a cylinder with a height of $100 \mathrm{~mm}$ (Figure 3). The basic physical parameters of the coal sample are shown in Table 1.

2.3. Test Results and Analysis. Steady state method was used to test coal permeability; the permeability of coal could be calculated as

$$
k=\frac{2 Q_{0} \cdot p_{0} \cdot \mu \cdot L}{A \cdot\left(p_{1}^{2}-p_{2}^{2}\right)},
$$

where $k$ is the permeability of coal, $Q_{0}$ is the gas volume flow rate at the outlet under the standard state, $\mu$ is the dynamic viscosity coefficient of the gas, $L$ is the length of coal sample, $A$ is the cross-sectional area of the coal sample, $p_{1}$ is the gas pressure at the inlet end, and $p_{2}$ is the gas pressure at the outlet.

Figure 4 shows the deviatoric stress, axial strain, radial strain, and volumetric strain of the six loading schemes. At the initial loading stage and the first loading stage, the coal samples occur in the elastic deformation. The volumetric deformation is in the compression state. In the yield and failure stages, the coal samples expand significantly. The deviatoric stress decreases, and the strains continue to increase. Different loading conditions lead to different stress-strain relationships of coal samples, which indicate that the mechanical behaviors of the mining coal are different due to different distances between the coal and the reverse fault.

In the first group, when the stress concentration coefficient of mining coal increases gradually, the peak value of deviatoric stress is low for coal sample M1. This is because the axial stress has a low loading rate and the same unloading rate as that of the confining pressure, which leads to lower confining pressure and lower strength and decreases ductility 


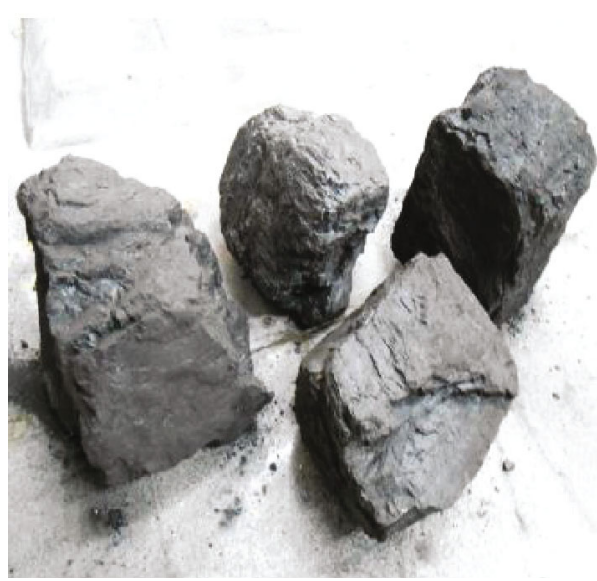

(a) Collected test coal

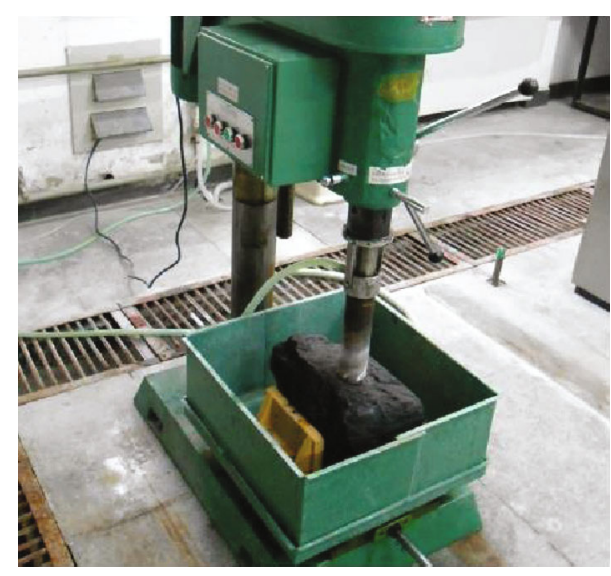

(b) Borehole sampler

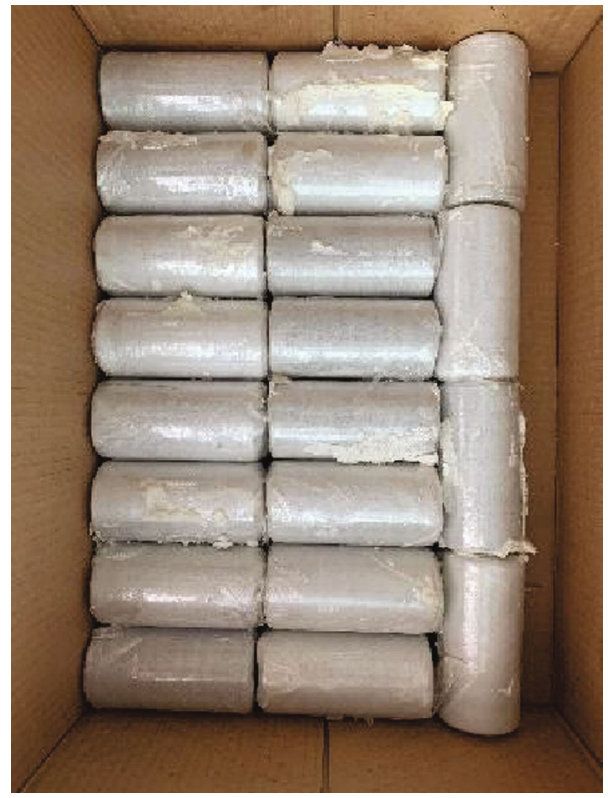

(c) Trial coal sample

FIGURE 3: The collected coal, borehole sampler, and trial coal sample.

TABle 1: Physical parameters of coal specimens.

\begin{tabular}{lccccc}
\hline Sample number & Diameter $(\mathrm{mm})$ & Height $(\mathrm{mm})$ & Volume $\left(\mathrm{cm}^{3}\right)$ & Mass $(\mathrm{g})$ & Density $\left(\mathrm{g} / \mathrm{cm}^{3}\right)$ \\
\hline M1 & 50.30 & 96.03 & 190.82 & 252.77 & 277.40 \\
M2 & 49.57 & 104.18 & 1.32 & 236.75 & 1.38 \\
M3 & 50.18 & 88.56 & 175.14 & 269.94 & 1.35 \\
M4 & 50.59 & 98.51 & 198.02 & 278.75 & 1.36 \\
M5 & 50.15 & 103.64 & 204.72 & 225.01 & 1.36 \\
M6 & 50.38 & 85.90 & 171.24 & & 1.31 \\
\hline
\end{tabular}

in the axial loading process. The coal trends to damage with a lower confining pressure. Sample M3 has a high peak value of deviatoric stress because of the high loading rate of axial stress and the corresponding high confining pressure in the axial loading process. The axial strain, radial strain, and volumetric strain of coal sample M3 at the peak position of deviatoric stress are the highest, and the volumetric strain is correspondingly large after complete destruction. It is concluded that when the distance between the mining coal and the reverse fault decreases and the stress concentration coefficient of the coal increases gradually, the deviatoric stress peak and strain increase.

In the second group, the deviatoric stress peak value of sample M6 is the smallest due to the lowest axial compression 


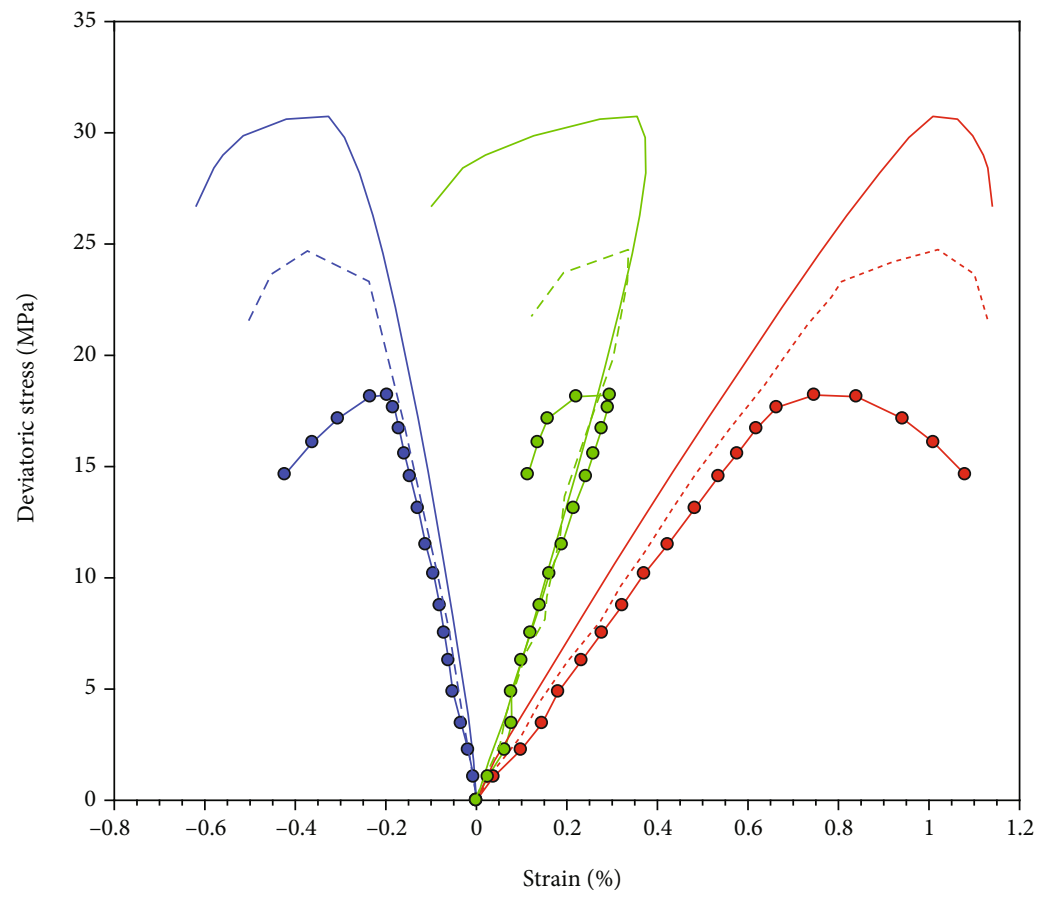

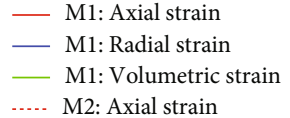

..... M2: Axial strain

- M3: Volumetric strain
.... M2: Radial strain

M2: Volumetric strain

- M3: Axial strain

- M3: Radial strain

(a)

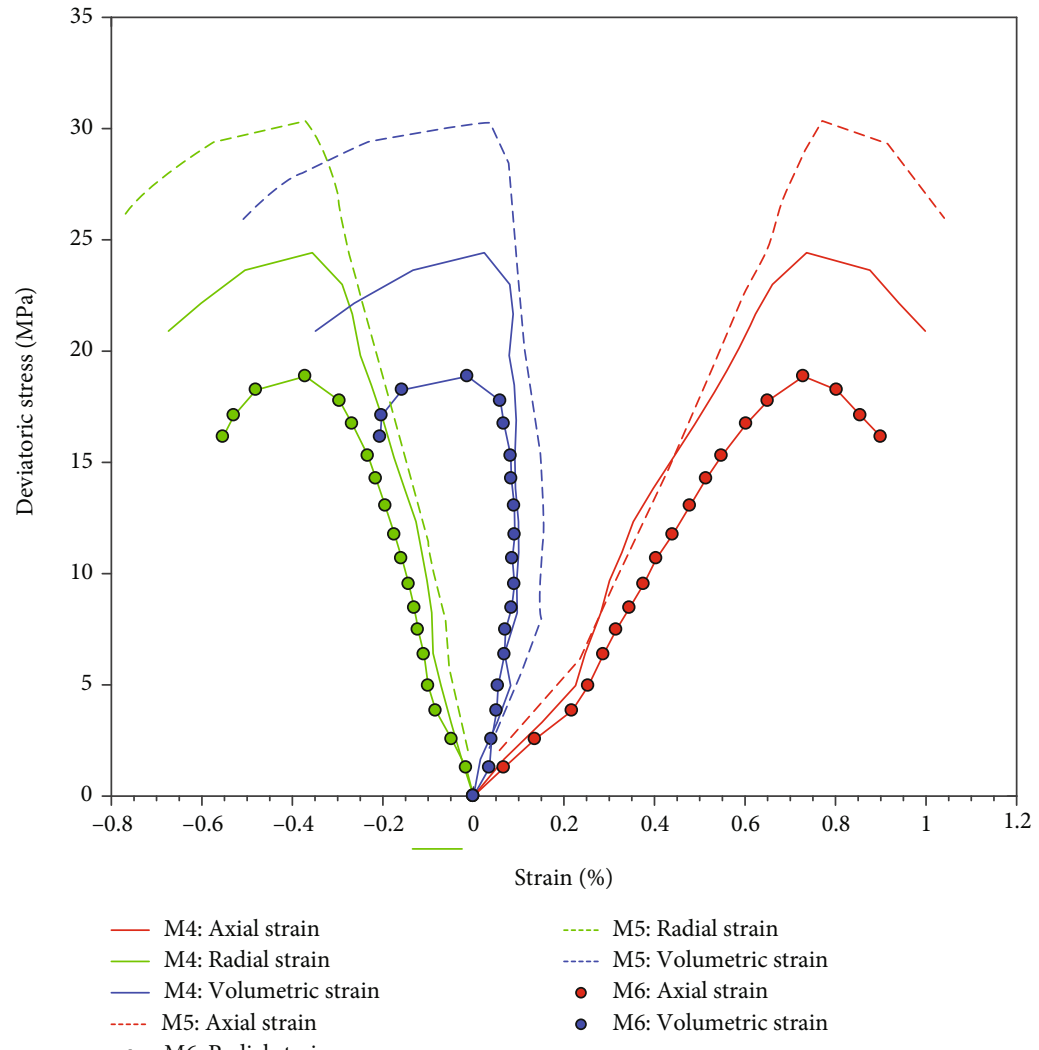

(b)

FIGURE 4: Deviatoric stress-strain of (a) samples M1, M2, and M3 and (b) samples M4, M5, and M6. 
TABLE 2: Physical parameters of the test.

\begin{tabular}{|c|c|c|c|c|c|c|c|}
\hline \multirow{2}{*}{ Loading schemes } & \multirow{2}{*}{ Coal sample } & \multirow{2}{*}{$\begin{array}{l}\text { Distance between mining } \\
\text { coal and reverse fault }(\mathrm{m})\end{array}$} & \multirow{2}{*}{$\begin{array}{c}\text { Peak value of deviatoric } \\
\text { stress }(\mathrm{MPa})\end{array}$} & \multicolumn{4}{|c|}{ Location of peak damage } \\
\hline & & & & $\sigma_{3}(\mathrm{MPa})$ & $\varepsilon_{1}(\%)$ & $\varepsilon_{3}(\%)$ & $\varepsilon_{v}(\%)$ \\
\hline Scheme 1 & M1 & 65 & 18.21 & 5.70 & 0.74 & -0.20 & 0.25 \\
\hline Scheme 2 & M2 & 35 & 24.75 & 6.12 & 1.02 & -0.38 & 0.27 \\
\hline Scheme 3 & M3 & 5 & 30.73 & 6.57 & 1.01 & -0.33 & 0.35 \\
\hline Scheme 4 & M4 & 65 & 24.42 & 6.31 & 0.76 & -0.36 & 0.02 \\
\hline Scheme 4 & M5 & 35 & 30.35 & 6.77 & 0.73 & -0.35 & 0.03 \\
\hline Scheme 5 & M6 & 5 & 18.86 & 6.15 & 0.72 & -0.37 & -0.02 \\
\hline
\end{tabular}

loading rate. Sample M5 has the largest peak value of deviatoric stress for the largest axial compression loading rate. Both deviatoric stress peak and strain increase and then decrease as the stress concentration coefficient of coal rises and then goes down.

Table 2 lists the mechanical parameters in the two groups of tests. Compared with sample M1, the deviatoric stress peak and axial strain of sample M3 increase by $40.74 \%$ and $26.73 \%$, respectively. Compared with sample M4, the peak deviatoric stress and axial strain of coal sample M6 decrease by $29.48 \%$ and $5.55 \%$, respectively. With the same confining pressure, a higher axial compression loading rate results in larger deviatoric stress peak and ductile deformation.

Figure 5 shows the curves of volumetric strain and permeability of coal samples under different loading schemes. In the prepeak stage, the coal sample is compacted with the increase of stress. When the internal fracture is nearly closed, the volume of the coal samples is compressed and the volume strain and permeability decrease. In the postpeak stage, the coal sample reaches the peak of deviatoric stress with the further increase of stress. The new fractures are generated at the same time. The coal sample is damaged until the coal sample was destructed. The volume strain and permeability of the coal sample increase and reach the maximum.

The permeability of samples M1, M2, and M3 increases by $22.1 \%, 28.0 \%$, and $36.7 \%$, respectively. The distance between mining coal and reverse fault decreases, and the stress concentration coefficient of coal body gradually increases. The enhancement of coal permeability is inversely proportional to the distance from the reverse fault. The closer is the distance to the reverse fault, the greater is the increment of coal permeability. The permeability of M4, M5, and M6 coal samples increases by $23.6 \%, 37.2 \%$, and $20.8 \%$, respectively, associated with the corresponding changes of the stress concentration of coal.

\section{Permeability Model of Mining Coal with the Reverse Fault Area}

Due to the long-term tectonic stress loading on the coal in the area near the reverse fault, the fracture and pore structures inside the coal seam change. The dip angle, drop, and other factors of the reverse fault would affect the coal stress under the mining. Therefore, the permeability of the coal is related to the stress. In this section, the coal is simplified as the double-pore structure with pores and fractures, which refer to the coal matrix containing micropores and the fracture network, respectively.

3.1. Permeability Model of Mining Coal at Prepeak Stage. In the prepeak stage, the coal body is deformed with the combination of gas adsorption and desorption, tectonic stress, and mining stress. The coal body is assumed to be a continuous, uniform, and isotropic medium. The deformation of coal accords with the hypothesis of small deformation. The ideal gas flow in the coal seam is assumed to be an isothermal process without considering the influence of temperature.

The permeability of gas flow in the coal seam is mainly attributed to the fracture network in the coal seam, while the contribution of matrix micropores is ignored. Therefore, it is assumed that the mechanical behavior of the coal under stress is mainly caused by the change of fracture inside the coal. The coal matrix containing micropores is regarded as the solid skeleton of the porous elastic coal seam. Thus, the coal is treated as the porous medium. According to the definition of the porosity of porous media, the fracture porosity of coal is given as [23]

$$
\varnothing=\frac{V_{f}}{V_{b}}
$$

where $V_{b}$ is the volume of coal $\left(\mathrm{m}^{3}\right)$ and $V_{f}$ is the volume of the coal fracture.

From Equation (2), we have

$$
d \varnothing=d\left(\frac{V_{f}}{V_{b}}\right)=\frac{V_{f}}{V_{b}}\left(\frac{d V_{f}}{V_{f}}-\frac{d V_{b}}{V_{b}}\right) .
$$

Submitting Equation (2) into (3), Equation (3) is rewritten as

$$
\frac{d \varnothing}{\varnothing}=d \varepsilon_{v b}-d \varepsilon_{v f}
$$

where $d \varepsilon_{v b}=-\left(d V_{b} / V_{b}\right)$ is the change of coal volume strain and $d \varepsilon_{v f}=-\left(d V_{f} / V_{f}\right)$ is the variation of the volume strain of the coal fracture.

The volumetric strain of coal is assumed to be affected by the average stress of coal $\sigma_{m}$. Therefore, the volume and fracture deformation of the coal under the combined of average stress change $d \sigma_{m}$ and gas pressure change $d p$ are analyzed to derive the volume strain changes of the coal. The stress 


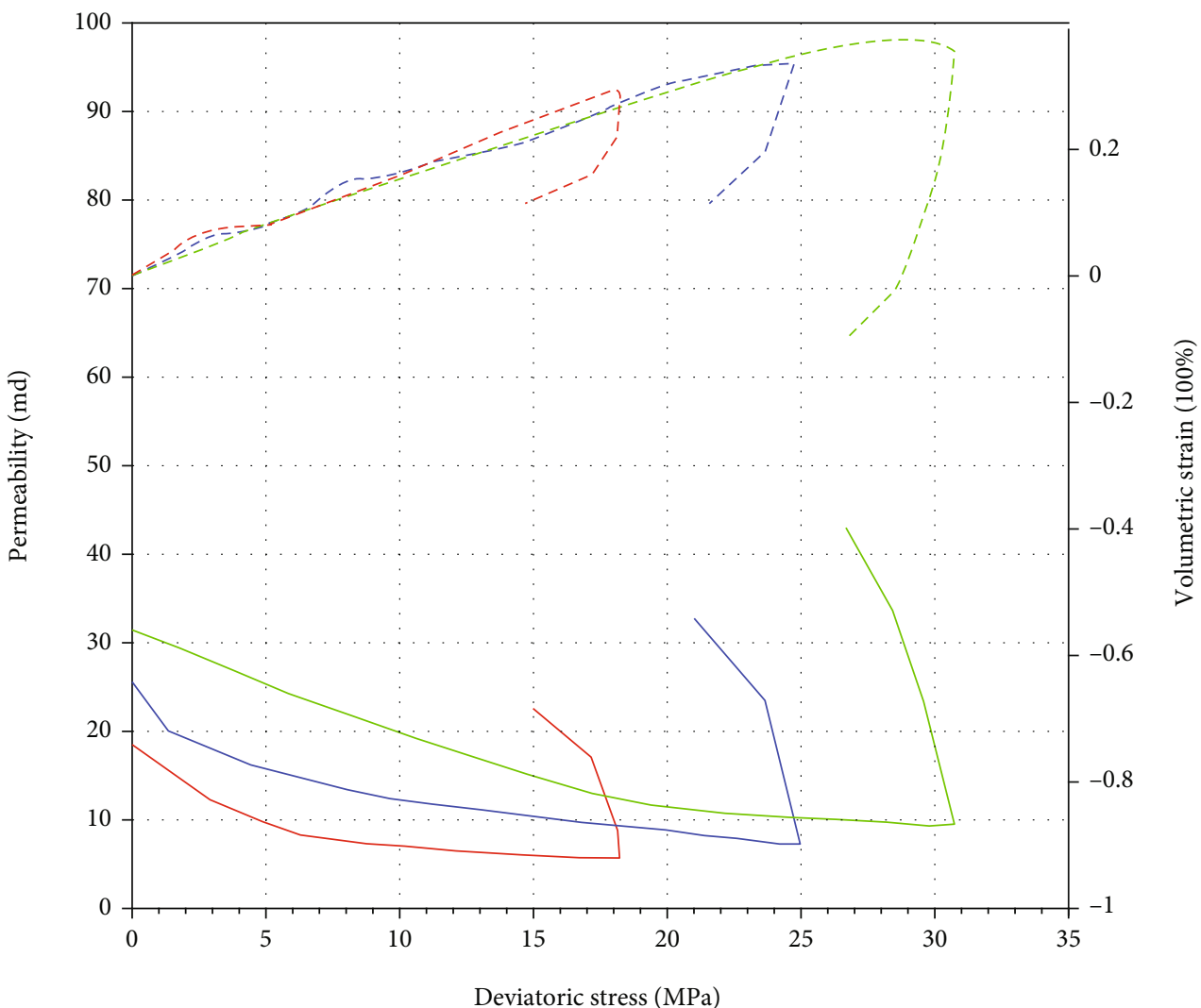

M1: Permeability

- - M1: Volumetric strain

- - M2: Volumetric strain

- _ M3: Volumetric strain

(a)

Figure 5: Continued. 


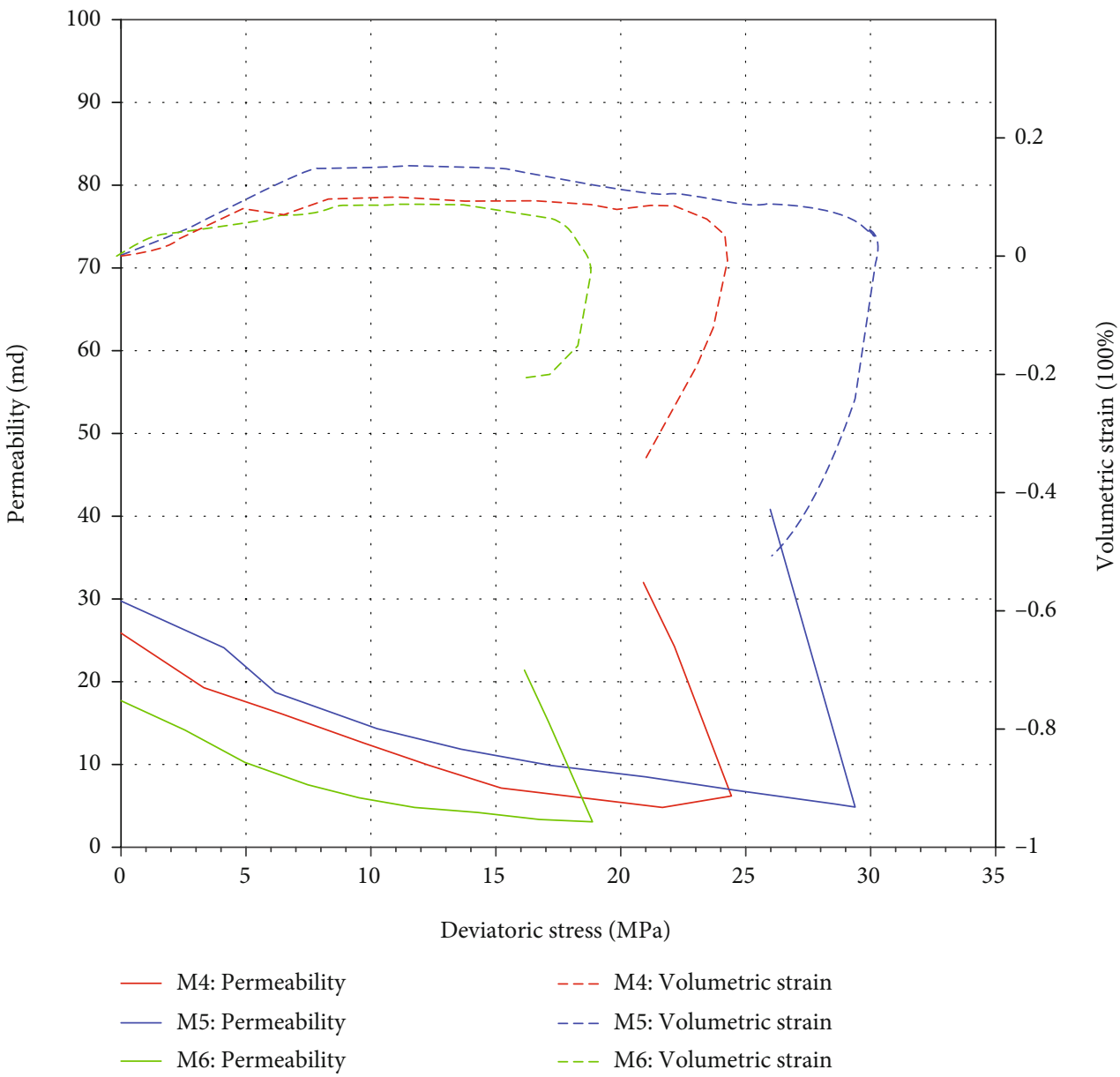

(b)

FIGURE 5: Relationship between volumetric strain permeability and deviatoric stress during the process.

states of the average stress change amount $d \sigma_{m}$ and the gas pressure change amount $d p$ are assumed to be the superposition of the two stress states. At first, the coal is affected by the pore gas pressure change $d p$ and the same amount of pressure change $d p_{c}=d p$. Then, the coal body is subjected to pressure change $d p_{d}=d \sigma_{m}-d p$ with the change of pore gas pressure of zero. The schematic diagram of stress state decomposition of the representative fracture element in coal is shown in Figure 6 [24].

For the first load, the gas pressure inside the coal fracture changes. Meanwhile, the influence of gas adsorption in the coal is considered. The volumetric strain change of the coal is decomposed into the volumetric strain change of coal induced by mechanical action $d \varepsilon_{v b}^{m}$ and the volumetric strain change of coal induced by gas adsorption $d \varepsilon_{v b}^{s}$. The volumetric strain change of the coal fracture is decomposed into the volumetric strain change of the coal fracture caused by mechanical part $d \varepsilon_{v f}^{m}$ and the volumetric strain change of coal fracture caused by gas adsorption $d \varepsilon_{v f}^{m}$, namely,

$$
\begin{gathered}
d \varepsilon_{v b}^{1}=d \varepsilon_{v b}^{m}+d \varepsilon_{v b}^{s}, \\
d \varepsilon_{v f}^{1}=d \varepsilon_{v f}^{m}+d \varepsilon_{v f}^{s} .
\end{gathered}
$$

The volumetric strain change of coal $d \varepsilon_{v b}^{m}$ with the first load is expressed as

$$
d \varepsilon_{v b}^{m}=\frac{d p}{K_{s}},
$$

where $1 / K_{s}=-\left(1 / V_{b}\right)\left(\partial V_{b} / \partial p\right)_{\left\{p_{d}, \varepsilon_{v b}^{s}\right\}}$. Let $K_{s}$ be equal to $K_{m}$. $K_{m}$ is the bulk modulus of the coal matrix. Equation (7) is changed into

$$
d \varepsilon_{v b}^{m}=\frac{d p}{K_{m}} .
$$

Under the first loading condition, the volume strain change variable $d \varepsilon_{v f}^{m}$ caused by mechanical action is expressed as

$$
d \varepsilon_{v f}^{m}=\frac{d p}{K_{\varnothing}},
$$

where $1 / K_{\varnothing}=-\left(1 / V_{f}\right)\left(\partial V_{f} / \partial p\right)_{\left\{p_{d}, \varepsilon_{v f}^{s}\right\}}$. Since small deformation occurs in the coal, we consider that the parameter $K_{\phi}$ is 


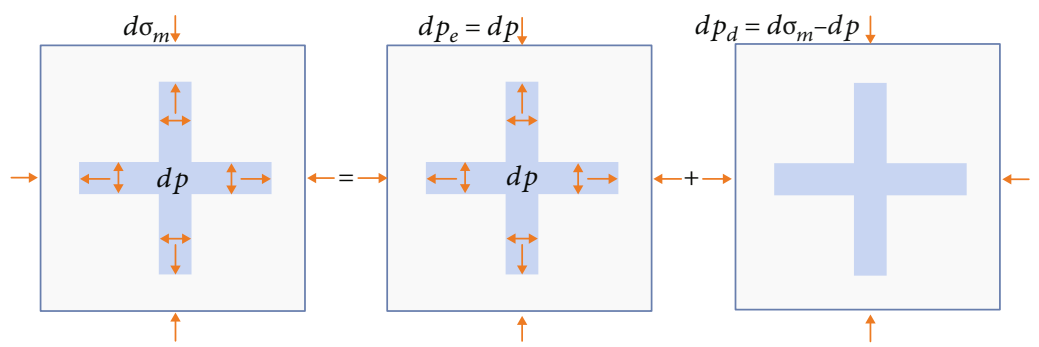

FIGURE 6: Stress state decomposition diagram of representative fracture element.

equal to the volume modulus of the coal matrix $K_{m}$. Therefore, Equation (8) could be changed into

$$
d \varepsilon_{v f}^{m}=\frac{d p}{K_{m}}
$$

By substituting Eq. (8) into Eq. (5), the volume strain change of coal under the first load is obtained as follows:

$$
d \varepsilon_{v b}^{1}=\frac{d p}{K_{m}}+d \varepsilon_{v b}^{s}
$$

By substituting Equation (9) into Equation (5), the volume strain change of the coal fracture under the first load is obtained as follows:

$$
d \varepsilon_{v f}^{1}=\frac{d p}{K_{m}}+d \varepsilon_{v f}^{s}
$$

In the case of the second load, the change amount of the gas pressure in the coal body is zero. The change amount of the coal volume strain induced by gas adsorption and the change amount of the fracture volume are neglected. The change of the coal volume strain under the second load is expressed as [25]

$$
d \varepsilon_{v b}^{2}=\frac{d \sigma_{m}-d p}{K}
$$

where $1 / K=-\left(1 / V_{b}\right)\left(\partial V_{b} / \partial p_{d}\right)_{\left\{p, \varepsilon_{v b}^{s}\right\}}$ and $K$ is the bulk modulus of the coal.

The volumetric strain change of the coal fracture under the second load is given as

$$
d \varepsilon_{v f}^{2}=\frac{d \sigma_{m}-d p}{K_{f}}
$$

where $1 / K_{f}=-\left(1 / V_{f}\right)\left(\partial V_{f} / \partial p_{d}\right)_{\left\{p, \varepsilon_{v f}^{s}\right\}}$ and $K_{f}$ is the fracture bulk modulus of the coal.

According to the superposition principle, the volumetric strain change of coal is obtained as

$$
d \varepsilon_{v b}=\frac{d \sigma_{m}-d p}{K}+\frac{d p}{K_{m}}+d \varepsilon_{v b}^{s}
$$

The volume strain change of the coal fracture is

$$
d \varepsilon_{v f}=\frac{d \sigma_{m}-d p}{K_{f}}+\frac{d p}{K_{m}}+d \varepsilon_{v f}^{s}
$$

Substituting Equations (15) and (16) into Equation (4), we have

$$
\frac{d \varnothing}{\varnothing}=\left[\left(\frac{1}{K}-\frac{1}{K_{f}}\right)\left(d \sigma_{m}-d p\right)+\left(d \varepsilon_{v b}^{s}-d \varepsilon_{v f}^{s}\right)\right] .
$$

In the prepeak stage, the volume modulus $K$ and the coal fracture volume modulus $K_{f}$ are regarded as constants. Integrating Equation (17) with time, we get

$$
\begin{aligned}
\frac{\varnothing}{\varnothing_{0}}= & \exp \left\{\left(\frac{1}{K}-\frac{1}{K_{f}}\right)\left[\left(\sigma_{m}-\sigma_{m 0}\right)-\left(p-p_{0}\right)\right]\right. \\
& \left.+\left[\left(\varepsilon_{v b}^{s}-\varepsilon_{v b 0}^{s}\right)-\left(\varepsilon_{v f}^{s}-\varepsilon_{v f 0}^{s}\right)\right]\right\},
\end{aligned}
$$

where the subscript 0 represents the parameter under the initial stress condition.

For the coal seam containing gas, the adsorption/desorption of gas causes expansion/contraction of the coal body. The coal volume strain caused by gas adsorption/desorption is expressed as

$$
\varepsilon_{v b}^{s}=-\frac{3 a \cdot \rho_{m} \cdot R \cdot T \cdot \ln (1+b p)}{E_{A} \cdot V_{A}},
$$

where $\rho_{m}$ is the density of coal, $R$ is the general gas constant, $T$ is the absolute temperature, $V_{A}$ is the molar volume of the gas, $a$ is the limit adsorption capacity at the reference pressure, $b$ is the adsorption equilibrium constant of coal, and $E_{A}$ is the adsorption swelling modulus of coal matrix.

The adsorption/desorption of the coal gas not only causes the volume deformation of the coal matrix but also leads to the volume change of the coal fracture. It is generally assumed that the adsorption/desorption deformation of the coal body completely affected the volume deformation of the coal matrix without causing the change of the fracture volume. Therefore, the influence of gas adsorption on the fracture deformation of coal is not considered. In addition, coal adsorption is stronger under the influence of the reverse fault. Ignoring this influence would affect the accuracy of 
permeability prediction. The related research results show that there are many inorganic minerals inside the coal fracture, which would hinder the deformation of the fracture. When the coal is deformed due to gas adsorption/desorption, the volume of the matrix of the coal changes. Meanwhile, the adsorption/desorption deformation of the coal affects the volume of the fracture. Therefore, to better characterize the permeability variations of mining coal with the reverse fault, the volume strain of coal caused by gas adsorption/desorption $\varepsilon_{v b}^{s}$ is used to represent the volume strain of coal fracture $\varepsilon_{v f}^{s}$, namely,

$$
\varepsilon_{v f}^{s}=\Psi\left(\varepsilon_{v b}^{s}\right)
$$

By expanding Equation (20) according to Taylor's formula at $\varepsilon_{v b}^{s}=\varepsilon_{v b 0}^{s}$, and discarding the higher-order trace above the second order, we get

$$
\varepsilon_{v f}^{s}=\varepsilon_{v f 0}^{s}+f\left(\varepsilon_{v b}^{s}-\varepsilon_{v b 0}^{s}\right)
$$

where $f=\left.\left(\partial \Psi / \partial \varepsilon_{v b}^{s}\right)\right|_{\varepsilon_{v b}^{s}-\varepsilon_{v b 0}^{s}}$ refers to the adsorption deformation coefficient of the coal fracture. In the prepeak stage, the adsorption deformation coefficient $f$ of the coal fissure is regarded as a constant.

By substituting Equation (21) into Equation (18), the porosity change of coal fracture is given as

$$
\begin{aligned}
\frac{\varnothing}{\varnothing_{0}}= & \exp \left\{\left(\frac{1}{K}-\frac{1}{K_{f}}\right)\left[\left(\sigma_{m}-\sigma_{m 0}\right)-\left(p-p_{0}\right)\right]\right. \\
& \left.+(1-f)\left(\varepsilon_{v b}^{s}-\varepsilon_{v b 0}^{s}\right)\right\} .
\end{aligned}
$$

According to the Kozeny-Carman equation, the relationship between coal permeability and porosity is expressed as [26]

$$
k=\frac{\varnothing^{3}}{C S^{2}(1-\varnothing)^{2}}
$$

where $C$ refers to Kozeny-Carman constant, which is related to the tortuosity of the fracture, and $S$ is the fracture surface area per unit volume of porous media. In the prepeak stage, since the coal has small deformation, $C$ and $S$ are regarded as constants. Based on the Kozeny-Carman equation, the evolution of coal permeability is obtained:

$$
\frac{k}{k_{0}}=\left(\frac{\varnothing}{\varnothing_{0}}\right)^{3}\left(\frac{1-\varnothing_{0}}{1-\varnothing}\right)^{2}
$$

Since the porosity of the fracture is generally less than $10 \%$, which is far less than 1 , therefore, the second item on the right of Equation (24) is ignored. The relationship between permeability and porosity is expressed as [12]

$$
\frac{k}{k_{0}}=\left(\frac{\varnothing}{\varnothing_{0}}\right)^{3} \text {. }
$$

By substituting Equation (22) into Equation (25), the permeability of coal at the prepeak stage is obtained:

$\frac{k}{k_{0}}=\exp \left\{3\left[-c_{f}\left[\left(\sigma_{m}-\sigma_{m 0}\right)-\left(p-p_{0}\right)\right]+(1-f)\left(\varepsilon_{v b}^{s}-\varepsilon_{v b 0}^{s}\right)\right]\right\}$,

where $C_{f}$ is the compression coefficient of the coal fracture.

Equation (26) can be rewritten as [17]

$$
k=k_{0} \cdot \exp \left[-3 c_{f}\left(\sigma_{e}-\sigma_{e 0}\right)\right]
$$

where the effective stress of coal $\sigma_{e}=\sigma_{m}-p+(1-f)\left(\varepsilon_{v b}^{s} / c_{f}\right)$.

3.2. Permeability Model of Mining Coal at Postpeak Stage. The stress state of the coal in the area near the reverse fault changes continuously with mining. The abutment pressure gradually increases from hydrostatic pressure to the peak value until the coal breaks. Under the influence of the reverse fault, the abutment pressure of mining coal changes. As the horizontal stress unloads, the damage and failure occur in coal, which affects the distribution and evolution of the coal fracture as well as characteristics of gas seepage.

Generally, the stress-dependent permeability model or strain-dependent permeability model is used to analyze the characteristics of gas seepage in mining coal. According to the gas seepage test results, when the mining coal enters the postpeak stage under the influence of the reverse fault, the damage and fracture occur inside the coal. The density of the fracture increases greatly. Currently, unrecoverable internal damage occurs to the coal. The increase of the fracture of the coal is also unrecoverable. Therefore, we consider the effects of effective stress and internal damage. The compression coefficient and adsorption deformation coefficient of the coal fracture is related to the fissure structure in the coal body. The relationship between the effective stress and permeability of coal changes gradually with the development of the damage of coal. In the continuum damage mechanics, the damage variable is used to describe the damage degree of the medium. Therefore, the damage variable could be used to reflect the degree of fissure development in the coal body. Then, by analyzing the relationship between the damage variable and permeability, the influence of the damage on the permeability of the coal is obtained. The damage variable is defined as

$$
D=1-\frac{E}{E_{0}}
$$

where $E$ is the secant elastic modulus corresponding to the current stress state in the total stress-strain curve. $E_{0}$ refers to the elastic modulus of coal in the initial state. 


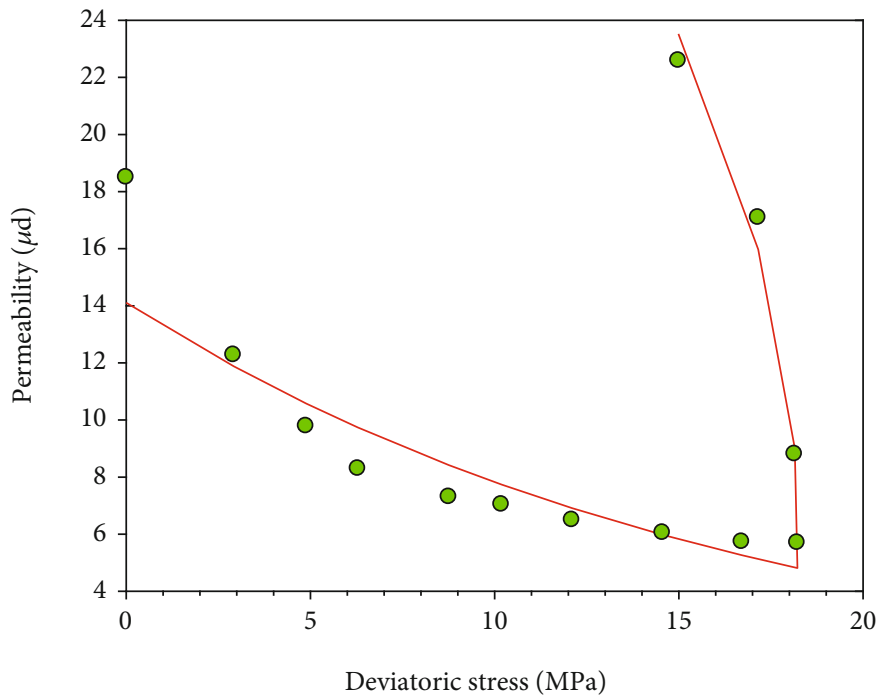

- M1: Calculated curve

- M1: Experimental date

(a)

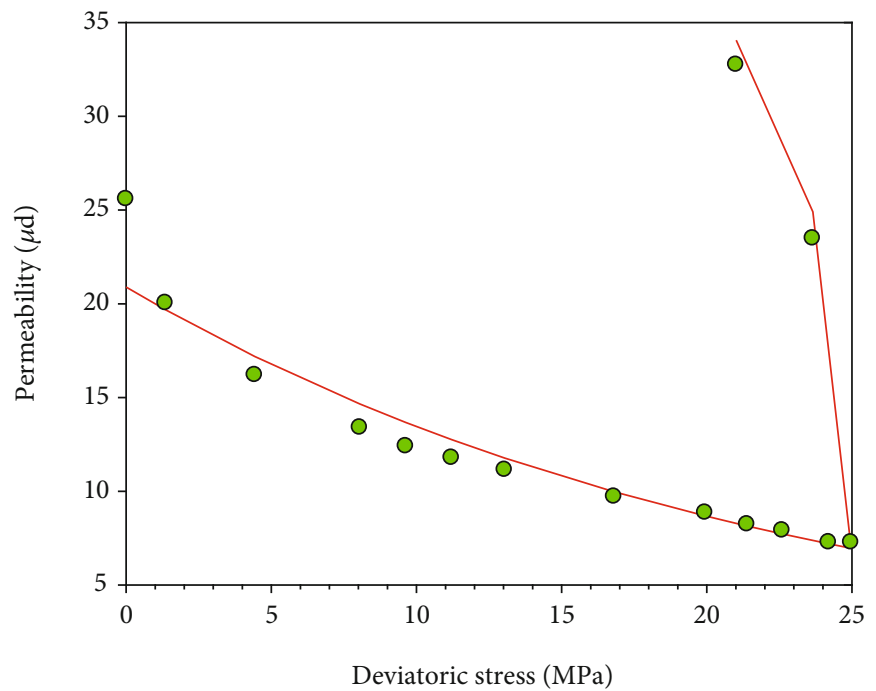

- M2: Calculated curve

- M2: Experimental date

(b)

Figure 7: Continued. 


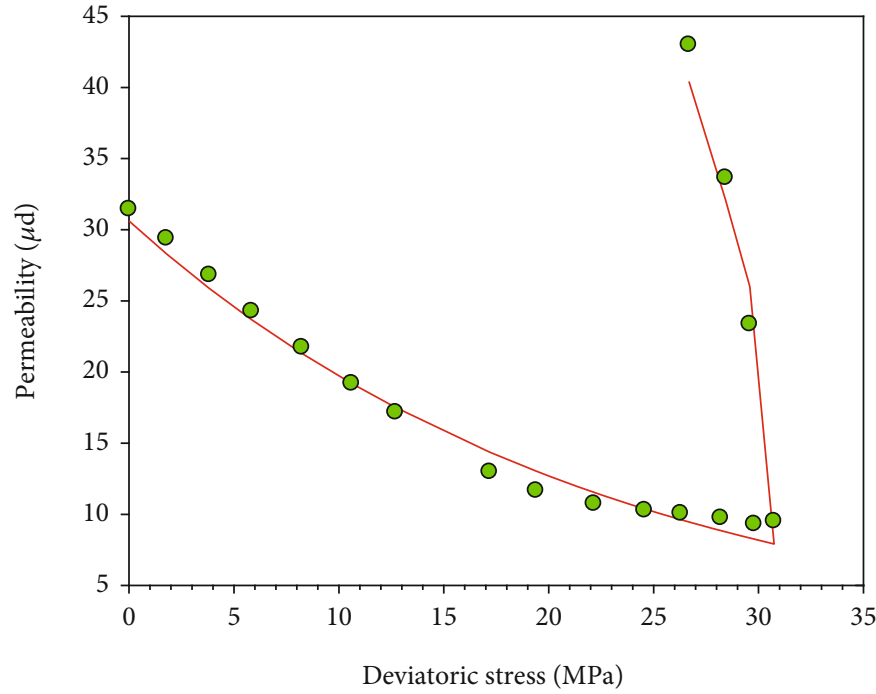

- M3: Calculated curve

- M3: Experimental date

(c)

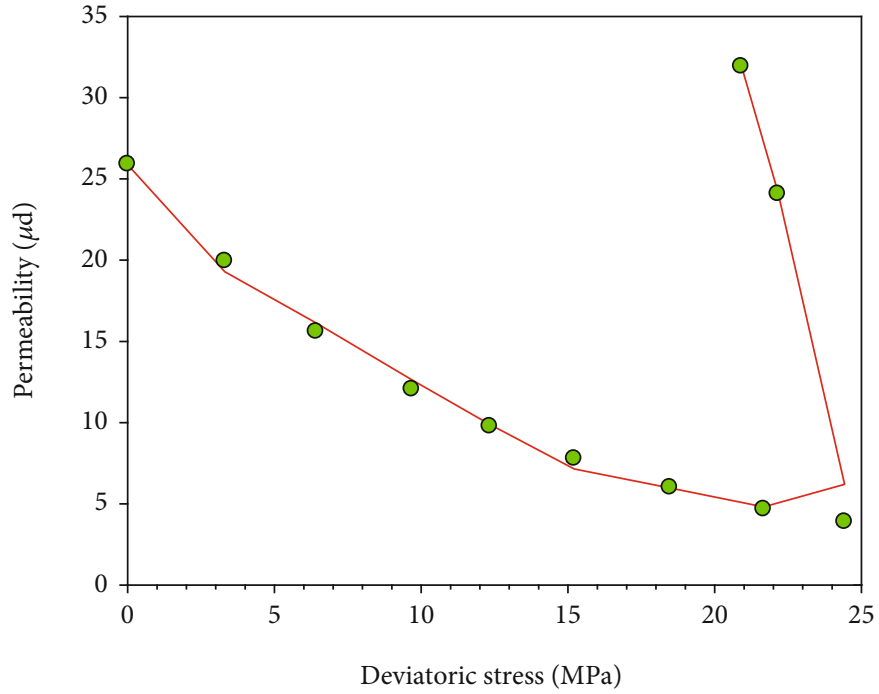

- M4: Calculated curve

- M4: Experimental date

(d)

Figure 7: Continued. 


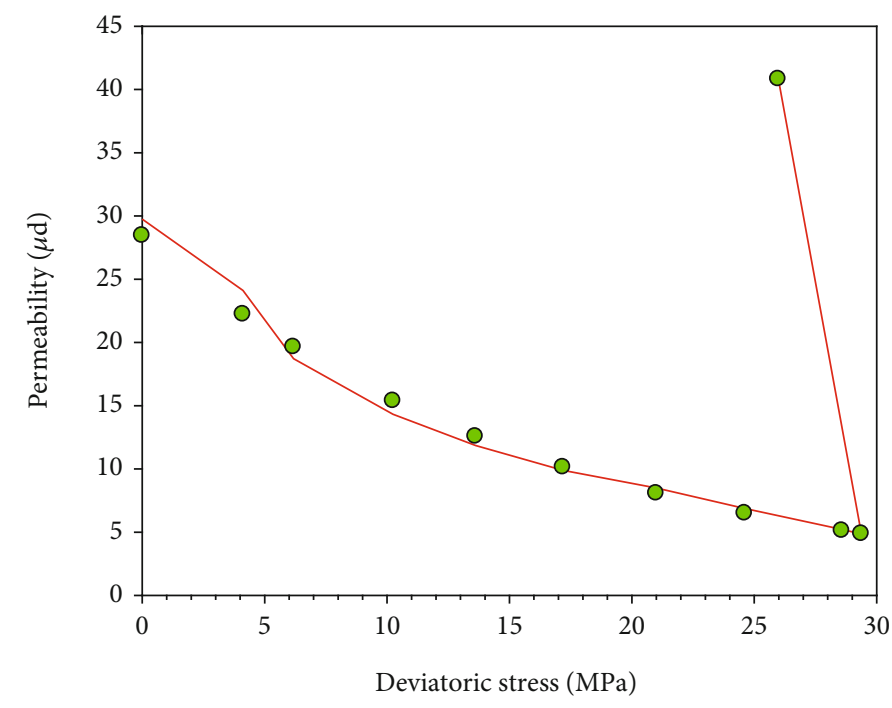

- M5: Calculated curve

- M5: Experimental date

(e)

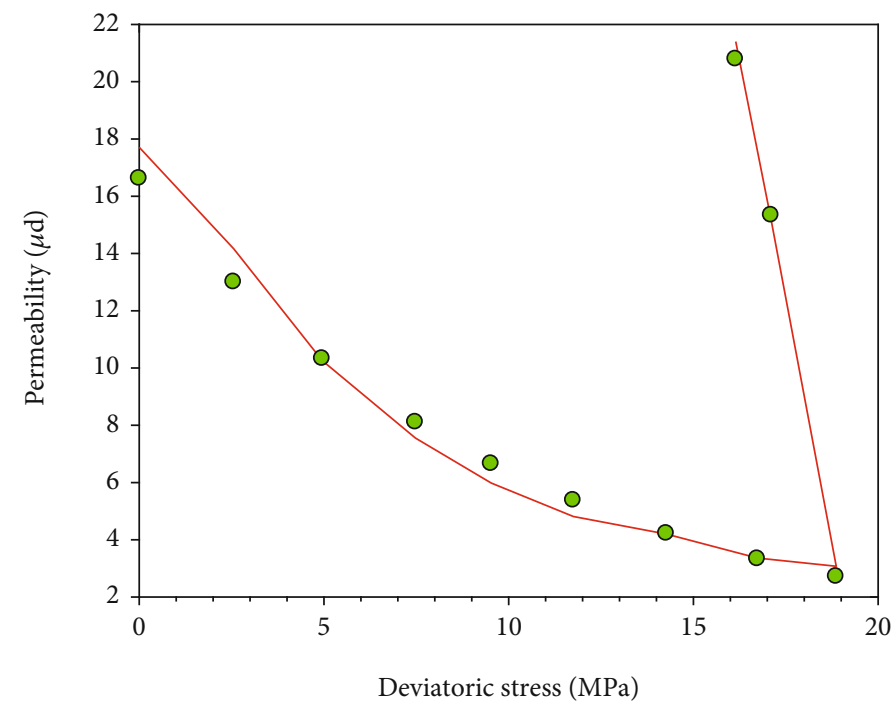

- M6: Calculated curve

- M6: Experimental date

(f)

FIgURE 7: Experimental and theoretical values of permeability and deviatoric stress.

At this stage, the change of gas permeability caused by coal damage and destruction has a linear relationship with the coal damage variable. In this case, the permeability equation of the coal body in the postpeak stage is expressed by multiplying the prepeak permeability equation by the correlation coefficient [27]. The evolution of permeability is written as

$$
\begin{aligned}
\frac{k}{k_{0}}= & (1+\gamma D) \exp \left\{3 \left[-c_{f}\left[\left(\sigma_{m}-\sigma_{m 0}\right)-\left(p-p_{0}\right)\right]\right.\right. \\
& \left.\left.+(1-f)\left(\varepsilon_{v b}^{s}-\varepsilon_{v b 0}^{s}\right)\right]\right\},
\end{aligned}
$$

where $\gamma$ is the influence coefficient of damage on permeability. By rewriting Equation (29) in the same form as Equation (27), we have

$$
k=k_{0} \bullet(1+\gamma D) \exp \left[-3 c_{f}\left(\sigma_{e}-\sigma_{e 0}\right)\right]
$$

Thus, the permeability model of the postpeak stage of mining coal under the influence of the reverse fault is deduced. By combining Equations (27) and (30), it can be found that the permeability of mining coal under the influence of the reverse fault presents an exponential growth trend with the stress at both prepeak and postpeak stages. The 
TABLE 3: Theoretical parameters of coal sample permeability calculation.

\begin{tabular}{lccc}
\hline Coal sample number & $C_{f}\left(\mathrm{MPa}^{-1}\right)$ & $\gamma$ & Fit degree \\
\hline M1 & 0.020 & 9.60 & 0.9910 \\
M2 & 0.015 & 7.79 & 0.9834 \\
M3 & 0.015 & 6.62 & 0.9902 \\
M4 & 0.026 & 12.65 & 0.9948 \\
M5 & 0.020 & 13.57 & 0.9925 \\
M6 & 0.032 & 15.51 & 0.9822 \\
\hline
\end{tabular}

influence of damage and fracture on gas seepage is considered in the permeability model of coal in the postpeak state, while is neglected in the prepeak state. In the prepeak stage, the permeability of coal depends on the elastic change of coal fracture volume, which is calculated by Equation (27). In the postpeak stage, coal permeability is affected by the postpeak damage variable, which is calculated by Equation (30).

3.3. Verification of the Permeability Model. To verify the accuracy of the proposed permeability model of coal, we compare the gas seepage tests results with the calculated results of the permeability model. The results are shown in Figure 7. The relevant parameters are listed in Table 3. Figure 7 shows that the permeability test data are basically consistent with the theoretical calculation results. During initial loading, the coal sample is in the prepeak stage, in which the coal fracture is gradually closed, and the permeability decreases. As the loads gradually increase to the peak value, the coal sample enters the postpeak stage, in which damage occurs, resulting in a new fracture. The increase in permeability accelerates the gas seepage. In both the prepeak stage and the postpeak stage, the permeability of coal samples varies exponentially with the stress, which demonstrates that the proposed permeability model has a good rationality and applicability. Overall, the verification results indicate that the permeability is suitable for the mining coal under the influence of the reverse fault.

\section{Conclusions}

In this paper, to study the role of the reverse fault on the permeability evolution in mining coal, we performed a gas seepage test with consideration of stress-loading and unloading schemes and proposed a permeability model, which involves the changes of permeability in the prepeak and postpeak stages. The main conclusions are derived:

(1) Permeability decreases in the prepeak stage and then increases in the postpeak stage. As the distance between mining coal and the reverse fault decreases, the stress concentration coefficient of coal increases gradually. In another case, the stress concentration coefficient of coal, as well as the deviatoric stress peak and strain, increases first and then decreases

(2) The test results show that the change of permeability is not only related to the failure deformation of coal but also closely related to the fracture propagation inside the coal. In the postpeak stage, damage occurs in the coal. The change of permeability has a linear relationship with the damage variable

(3) The permeability model of the mining coal under the influence of the reverse fault was established. The calculation expressions of the prepeak and the postpeak permeability of coal were deduced. The function of the coal volume strain caused by gas adsorption/ desorption was used to express the influence of gas adsorption/desorption on the coal fracture volume. The comparison between experimental data and the calculated result of the permeability demonstrates that the permeability model is capable of characterizing the permeability evolution of mining coal under the influence of the reverse fault

\section{Data Availability}

The data used to support the findings of this study are available from the first author upon request.

\section{Conflicts of Interest}

The authors declare that they have no conflicts of interest.

\section{Acknowledgments}

This work was supported by the National Key R\&D Program of China (No. 2018YFC0807900), the Science and Technology Innovation Project of the China Coal Technology Engineering Group (No. 2018-2-MS022), and the Liaoning Natural Science Foundation (No. 2020-KF-23-03).

\section{References}

[1] E. Stanislavsky and G. Garven, "A theoretical model for reverse water-level fluctuations induced by transient permeability in thrust fault zones," Earth and Planetary Science Letters, vol. 210, no. 3-4, pp. 579-586, 2003.

[2] M. Naeij, A. Soroush, and Y. Javanmardi, "Numerical investigation of the effects of embedment on the reverse fault-foundation interaction," Computers and Geotechnics, vol. 113, p. 103098, 2019.

[3] R. Foroozan, D. Elsworth, P. Flemings, F. Bilotti, and S. Muhuri, "The role of permeability evolution in fault zones on the structural and hydro- mechanical characteristics of shortening basins," Marine and Petroleum Geology, vol. 29, no. 1, pp. 143-151, 2012.

[4] A. Mazzoldi, A. P. Rinaldi, A. Borgia, and J. Rutqvist, "Induced seismicity within geological carbon sequestration projects: maximum earthquake magnitude and leakage potential from undetected faults," International Journal of Greenhouse Gas Control, vol. 10, pp. 434-442, 2012.

[5] T. Ma, H. Xu, W. Liu, Z. Zhang, and Y. Yang, "Coupled modeling of multiphase flow and poro-mechanics for well operations on fault slip and methane production," Acta Mechanica, vol. 231, pp. 3277-3288, 2020.

[6] Y. Liu, X. Li, S. Liu, P. Chen, and T. Yang, "Study on influence of fault structure on coal mine gas occurrence regularity based 
on the fractal theory: a case study of Panxi mine in China," Energy Sources, Part A: Recovery, Utilization, and Environmental Effects, vol. 17, pp. 1-11, 2019.

[7] W. Li, T. Ren, A. Busch et al., "Architecture, stress state and permeability of a fault zone in Jiulishan coal mine, China: implication for coal and gas outbursts," International Journal of Coal Geology, vol. 198, pp. 1-3, 2018.

[8] F. Anggara, K. Sasaki, S. Rodrigues, and Y. Sugai, "The effect of megascopic texture on swelling of a low rank coal in supercritical carbon dioxide," International Journal of Coal Geology, vol. 125, pp. 45-56, 2014.

[9] Y. Tan, Z. Pan, J. Liu et al., "Experimental study of impact of anisotropy and heterogeneity on gas flow in coal. Part I: diffusion and adsorption," Fuel, vol. 232, pp. 444-453, 2018.

[10] L. L. Wang, M. Vandamme, J. M. Pereira, P. Dangla, and N. Espinoza, "Permeability changes in coal seams: the role of anisotropy," International Journal of Coal Geology, vol. 199, pp. 52-64, 2018.

[11] S. Durucan and J. S. Edwards, "The effects of stress and fracturing on permeability of coal," Mining Science and Technology, vol. 3, no. 3, pp. 205-216, 1986.

[12] I. Gray, "Reservoir engineering in coal seams: part 1-the physical process of gas storage and movement in coal seams," SPE Reservoir Engineering, vol. 2, no. 1, pp. 28-34, 1987.

[13] S. Harpalani, Gas Flow through Stressed Coal, University of California, Berkeley, America, 1985.

[14] R. Puri and J. Seidle, "Measurement of stress-dependent permeability in coal and its influence on coalbed methane production," International Journal of Rock Mechanics and Mining Sciences \& Geomechanics Abstracts, vol. 30, no. 4, p. A223, 1993.

[15] J. P. Seidle, M. W. Jeansonne, and D. J. Erickson, “Application of matchstick geometry to stress dependent permeability in coals," in Society of Petroleum Engineers, pp. 433-444, Casper, Wyoming, 1992.

[16] I. Palmer and J. Mansoori, "How permeability depends on stress and pore pressure in coalbeds: a new model," SPE Reservoir Evaluation \& Engineering, vol. 1, no. 6, pp. 539-544, 1998.

[17] J. Shi and S. Durucan, "Drawdown induced changes in permeability of coalbeds: a new interpretation of the reservoir response to primary recovery," Transport in Porous Media, vol. 56, no. 1, pp. 1-16, 2004.

[18] T. Ma, W. Liu, J. Rutqvist, H. Zhang, and X. Zhao, “Anisotropy permeability model for highly fractured coal seams associated with coupled THM analysis of $\mathrm{CO}_{2}$-ECBM," Journal of China Coal Society, vol. 42, no. S2, pp. 407-416, 2017.

[19] X. Yongjun, "Numerical analysis for variation of coal gas seepage nearby fault at heading face," Journal of Liaoning Technical University, vol. 33, no. 4, pp. 447-450, 2014.

[20] Z. Zimin and Z. Yugui, "Investigation into coal-gas outburst occurred in Daping coalmine, by using theories of gasgeology," Journal of China Coal Society, vol. 30, no. 2, pp. 137-140, 2005.

[21] R. Zhou, Y. Qin, and Z. Zhang, "Distribution and variation of mining-induced stress in the reverse fault-affected coal body," Advances in Civil Engineering, vol. 30, no. 2, p. 140, 2005.

[22] C. Liang, Research on Failure Strain and Permeability Evolution of the Coal Ahead of Working Face and Its Application, China University of Mining \& Technology, Beijing, 2016.

[23] L. D. Connell, M. Lu, and Z. Pan, "An analytical coal permeability model for tri-axial strain and stress conditions," Inter- national Journal of Coal Geology, vol. 84, no. 2, pp. 103-114, 2010.

[24] J. Liu, Z. Chen, D. Elsworth, X. Miao, and X. Mao, "Evolution of coal permeability from stress-controlled to displacementcontrolled swelling conditions," Fuel, vol. 90, no. 10, pp. 2987-2997, 2011.

[25] R. W. Zimmerman, "Coupling in poroelasticity and thermoelasticity," International Journal of Rock Mechanics and Mining Sciences, vol. 37, no. 1-2, pp. 79-87, 2000.

[26] P. C. Carman, Flow of Gases through Porous Media, Butterworths Scientific Publications, London, 1956.

[27] Y. Xue, F. Gao, and X. Liu, "Effect of damage evolution of coal on permeability variation and analysis of gas outburst hazard with coal mining," Natural Hazards, vol. 79, no. 2, pp. 999$1013,2015$. 